\title{
Building Trust: Children Experiences with Food Allergies at Summer Camp
}

\author{
Sydney Leibel ${ }^{1}$, Nancy Fenton ${ }^{2}$ \\ ${ }^{1}$ School of Public Health and Health Systems, University of Waterloo, Waterloo, Canada \\ ${ }^{2} \mathrm{McMaster}$ Institute for Innovation \& Excellence in Teaching \& Learning (MIIETL) Mills Library L504, McMaster University, \\ Hamilton, Canada \\ Email: sleibel@ucsd.edu
}

How to cite this paper: Leibel, S. and Fenton, N. (2016) Building Trust: Children Experiences with Food Allergies at Summer Camp. Health, 8, 1423-1441.

http://dx.doi.org/10.4236/health.2016.814143

Received: April 13, 2016

Accepted: November 7, 2016

Published: November 10, 2016

Copyright $\odot 2016$ by authors and Scientific Research Publishing Inc. This work is licensed under the Creative Commons Attribution International License (CC BY 4.0).

http://creativecommons.org/licenses/by/4.0/

\begin{abstract}
Introduction: The objective of this study was to explore the experiences and perceptions of children with food allergies at summer camp. Methods: Qualitative drawand-tell interviews were conducted with 14 food allergic individuals aged 5 - 12 years to capture their lived experience with food allergies at summer camp. Results: Four key interdependent themes: trust, accommodation, proactive parents and coping strategies were identified in how children perceive their food allergies in unregulated summer camp environments.
\end{abstract}

\section{Keywords}

Food Allergy, Quality of Life, Anaphylaxis, Allergies

\section{(c) (i) Open Access}

\section{Introduction}

In 2013, a 13-year-old girl died from a fatal allergic reaction to peanuts at a summer camp in California, US. Similarly, in 2006 the death of a young girl in Ontario brought risk of anaphylaxis to the forefront of public policy. Both tragedies gained widespread media attention that led to the development of policies and recommendations to reduce fatal reactions for this at-risk group. Aspects of school policies, such as Sabrina's Law in Ontario have seeped into unregulated spaces in various manners as well [1].

A recent Canadian survey found $6.9 \%$ of children ( $<18$ years old) self-report at least one food allergy [2].

To address the needs of children with food allergies, summer camps have begun to adjust their policies to provide a safer environment for children with severe food allergies. The aim for many of these camps is to provide an equal opportunity for all children to develop meaningful social relationships and increase confidence. Summer camps 
have become a popular means of addressing the psychosocial needs of children with chronic disease to develop self-confidence, self-efficacy and independence [3] [4]. Yet, potential "life threatening" risks in such unregulated environments mean that many children with severe food allergies do not attend such camps. Indeed, Bollenger and colleagues, 2006, reported that as many as $26 \%$ of food allergic children's parents avoided letting their child go to camp [5]. Other research indicates that children and adolescents with chronic conditions (i.e., food allergy) are at heightened risk of social isolation, psychological distress and burden on quality of life (QOL). These findings were suggested by Wood and Mudd, 2011, who found increased distress and anxiety, in part, attributed to the exclusion and rejection from peers in such social activities as summer camp [1]. Furthermore, these authors suggest that social isolation, secondary to school and other environment policies, adversely affect self-esteem and self-efficacy. Therefore, it is crucial to explore various unregulated settings such as camps to understand how children experience the social and emotional aspects of being at risk of anaphylaxis in their day-to-day lives.

Most summer camps in Ontario, Canada are considered "nut-free" or "nut allergy friendly". In a climate of heightened concern about pervasive food ingredients, individuals with severe food allergies are considered at risk in public environments. Food allergy policies in such unregulated areas and stories in the popular press are evidences of the widespread awareness of food allergies as an important public health issue [6] and a mounting quality of life concern for children at risk of anaphylaxis. In particular, in this study we are interested in understanding how children at risk of anaphylaxis perceive the variable food allergy policies in unregulated spaces like camps and how they adapt to them.

\subsection{Health-Related Quality of Life}

Health-related quality of life highlights the social and emotional factors related to coping that modulate the personal burden of a health condition. This has been shown to have a profound effect on a child's day-to-day life [7] [8] [9]. Quality of life has been shown to be more impaired in children with food allergy than children with insulindependent diabetes mellitus. For instance, children with food allergies reported more fear, anxiety, and restrictions than children with diabetes [10]. Although diabetes has a greater potential to cause long-term complications and impacts on life expectancy, food allergy has a greater immediate impact on day-to-day functioning and health-related quality of life. A daily insulin regimen to manage diabetes may be bothersome, but it gives individuals some sense of control over their illness. Children and adolescents with food allergy live in a constant state of vigilance and uncertainty, due to the fear of exposure to the allergen. Similarly, Sicherer and colleagues, 2001, findings showed that food allergic children and adolescents (aged 5 to 18 years) experience significantly poorer results than their healthy counterparts for general health perception and parental perceptions of distress and worry [7]. The burden of avoidance and fear of an accidental exposure can increase anxiety and result in reduced health-related quality of life 
(HRQL) [11]. To date, there is a small body of exploratory work on experiences of risk [12] [13] [14] and psychological well-being among the food allergic population [15] [16] and even less research exploring health-related quality of life of food allergic children in unregulated physical settings such as summer camps.

The impact of food allergy on health-related quality of life (HRQL) was first examined using generic instruments. The findings revealed significant fear, anxiety, and restrictions in day-to-day activities associated with food allergy, especially in children aged 5 - 11 and their families [17]. In most cases, these effects were within the range expected for a potentially life-threatening disease. However, in some families the impact was significant, in that it interfered with normal psychosocial development of the child [18]. Disease-specific food allergy questionnaires tend to be more sensitive and responsive to issues around managing food allergies. For example, these tools can identify differences between subgroups, such as children with multiple food allergies versus those with a single food allergy. However, while several food allergy-specific questionnaires are now available, most still require longitudinal validation [19] [20] [21]. In addition, food allergy-specific questionnaires have not yet been used longitudinally to determine the impact of interventions on HRQL, although it remains one of the major measurement goals for using these instruments. While the Food Allergy Quality of LifeParental Burden (FAQL-PB) was the first validated food allergy-specific questionnaire developed to measure parental burden in families with a child with food allergy and did address the physical domain of camps, it is from the parent's point of view and not a direct measure of the child's perspective [22]. Other questionnaires, such as the Scale of Psychosocial factors in Food Allergy (SPS-FA) [23] and the Food Allergy Impact Scale (FAIS) [24] are neither validated nor from the child's perspective. For those less than 8 years of age, the Food Allergy Quality of Life Questionnaire-Parental Form (FAQLQPF) is utilized and is standardized for patients 0 - 12 years of age [25]. The Food Allergy Quality of Life Questionnaire-Child Form (FAQLQ-CF) questionnaire was the first food allergy-specific questionnaire developed for self-administration by children 8 to 12 years of age [26]. This tool addresses important issues around allergen avoidance, risk of accidental exposure, emotional impact, and dietary restrictions; however, it does not delve deeper into how children cope and adapt with their food allergies. In this regard, the FAQLQ-CF is quite limited in developing a deeper understanding of children with food allergies.

Despite these limitations, there has been significant progress in our understanding of children's experiences within some unregulated spaces such as the home [27] [28] and spaces of play [29] [30], however, there is a paucity of research related to unregulated environments such as camps, sporting events, and daycares where policies depend on the organization themselves. Even fewer studies have explored the emotional context of experiences of children at risk in these settings. Key contributions to this nascent area are primarily from children's geographers' through indirect reflection upon their own childhood and/or adulthood experiences [31] [32]. These studies have detailed the ways in which emotional aspects of everyday lives matter [33], but few studies directly ex- 
plore the emotional experiences of anaphylactic risk-scapes [34] [35]. This research study moves beyond a dictated policy response characteristic of current research by privileging the voices of affected children to understand their emotional experiences of summer camps spaces as unregulated settings.

\subsection{Research with Children}

By conducting research with children and rather than on them represents a recent paradigm shift [36] [37]. Traditionally, children's lives have been explored through the views of adults [37] thereby excluding them from the research process. Involving children as social actors in the research process has meant a revisiting of epistemologies and methodologies [38] [39] and shifting the gaze from viewing children as passive recipients to viewing them as active participants in constructing and determining their own experiences [39].

Methodological techniques, such as drawings, are considered effective methods to understand children's experiences thereby to "actively engage" them directly about issues that matter to them [40] [41]. In particular, the use of children's illustrations has a long history in psychiatry, psychology, and education [42] and is increasingly being used to explore children's life experiences [39]. These child-centered techniques [43] [44] have been shown benefit in at least three ways: 1) they help children organize their thoughts more effectively, particularly younger children [45] [46];2) they serve to address any power differences between adult researchers and children [36] and 3) they generate rich descriptions of lived experiences [38].

Research with children's drawings increasingly makes use of a variety of analytic techniques to interpret their experiences [41] [47] [48]. Mitchell used a critical visual methodology to analyze the content, production, and circulation of children's drawings [36]. An adaptation of this method was used to explore conditions of illness in children [46]. Finally, Kostenius and Ohrling employed a three-step phenomenological analytical approach: seeking meaning, theme analysis, and interpretation with reflection to analyze children's illustrations [47].

A meta-analysis of this literature has shown that asking young children to draw prior to being interviewed (draw-and-tell) is a robust strategy that facilitates memory performance, verbal reports of emotionally laden experiences, and more detailed narratives [44]. It is important to note that the use of drawings has been found to be inadequate as a stand-alone method; for drawings to be a useful research method, they are best used in dialogue [41] [45]. Health-related research with children is increasingly using interpretative methodologies in combination [45] [46] [47] [48] to explore psychosocial experiences. For example, research on asthma among inner-city school- aged children and their families used drawings, along with explanatory models, to explore beliefs about asthma [48]. Illustrations, along with interviews, were also used to explore experiences of childhood chronic illness [46], stressors of children with cancer [49], hospitalization of children with pervasive developmental disorder [50], and pain [51]. Sartain and colleagues used illustrations to explore childhood chronic illness and found that children were competent interpreters of their world [46]. 
Seldom do we consult with the impacted group when it comes to children. While children with severe food allergies at risk for anaphylaxis have been asked to complete surveys regarding their quality of life [10], very few studies have asked children to share the details of their experiences, their concerns, or their psychosocial stresses. This research attempts to fill this gap by directly engaging affected children in order to allow them to describe their experiences, their concerns, and their psychosocial stresses associated with the risk of anaphylaxis.

\section{Research Design and Methods}

This exploratory study employed a qualitative approach that included in-depth interviews and drawings to investigate the experiences and perceptions of food allergic children. Inclusion criteria included children age 5 - 12 years old with a history of physician diagnosed food allergy, attending summer camps in 2015, in the Province of Ontario, Canada that could be contacted by phone or email. We excluded patients under 5 years of age and those with unclear or mixed history of IgE mediated food allergy (i.e. celiac disease, eosinophilic esophagitis, lactose-intolerance). The sample was recruited utilizing the Anaphylaxis Canada Registry (now Food Allergy Canada), a non-profit organization that provides information for families dealing with life threatening allergies. Anaphylaxis Canada sent out a "Call for Participation" from this registry. Upon contact with researchers, parents were asked to provide consent for their child or adolescent to participate in the study. Permission, in the form of "assent", was also provided by children and adolescents. The study design was approved by the University of Waterloo (Ontario, Canada) Ethics Board.

After receiving parental consent, children were asked to draw a picture that illustrates "what it was like to have a food allergy while at a summer camp". Two weeks later, they participated in a 45-minute face-to-face interview. In advance of the interviews, a copy of the questions was sent to parents in order to assess the type of questions their children would be asked. The interviews were conducted after the child returned home from attending summer camp, at a location most convenient for them.

The researcher asked general questions about types of food allergy, experiences dealing with a food allergy at home, school and at camp, feelings about living with a food allergy. Then, questions were focused on living with food allergies and various coping strategies experienced in different physical contexts, e.g., regulated and non-regulated environments (home, school, camp). This discussion explored particular safe and unsafe locations within camp. Interview questions were adapted from the validated Food Allergy Quality of Life-Child Form (FAQLQ-CF) for children (age 8 - 12) and expanded to include topics around summer camp.

All interviews were audio-recorded, transcribed verbatim, viewed for consistency by two researchers, and member-checked with participants for their confirmation. Thematic analysis involving the creation and application of codes using NVivo 10, a validated analysis software package used to manage, code, and structure qualitative data was utilized [52]. A theme code set was created both deductively (based on the research 
objectives and interview guides) and inductively (themes emerging from the interview transcripts). Coding was assessed for inter- and intra-rater reliability [53], achieving $80 \%$ agreement with a second coder. Key themes appeared with the greatest frequency as discrete units of text in the interview transcripts.

\section{Results}

In total, 14 subjects, pseudonyms used, with physician-diagnosed food allergies were interviewed. The sample included 8 males and 6 females with an age range from 5 to 12 years old. Of the 14 participants, 7 had a history of food anaphylaxis and epinephrine administration. Six children had recently attended an overnight camp and the remaining eight attended day camps only. All camp locations were in the Province of Ontario, Canada and participants were largely from the metropolitan cities of Toronto and Ottawa. Results summarized in Table 1.

The thematic analysis of the in-depth interviews, along with the illustrations uncovered four prominent themes: 1) Trust; 2) Camp Accommodation; 3) Coping Mechanisms, and 4) Proactive parents. The first two themes of building trust and camp accommodation are interrelated given that the more camps accommodated, the more trust seemed to be built. The second two themes, coping mechanisms and proactive parents are also interrelated, as proactive parents seemed to foster more adaptive coping mechanisms for their children. Moreover, all four major themes interact and play complementary roles in how these children perceived the experience in the summer camp setting.

Table 1. Participant characteristics $(\mathrm{n}=14)$.

\begin{tabular}{ccc}
\hline Participant characteristics & Number of participants \\
\hline \multirow{2}{*}{ Gender } & Male & 8 \\
& Female & 6 \\
Age group & $5-7$ & 5 \\
& $8-10$ & 4 \\
& $11-12$ & 5 \\
& Peanut & 13 \\
Allergy & Tree nut & 9 \\
& Egg & 5 \\
& Milk & 2 \\
& Sesame & 5 \\
Type of camp & Shellfish & 4 \\
& Overnight & 6 \\
& Day camp & 8 \\
\hline
\end{tabular}

${ }^{\text {aS }}$ um in not equal to number of participants due to multiple responses. 


\subsection{Trust}

A major theme stemming from all the interviews centered on the concept of trust. Specifically, children discussed the kinds of camps they trusted, who they trusted most at camp, as well as events and places at the camps that increased or decreased their level of trust. Jessica, an 11-year-old girl allergic to peanut and sesame, drew a picture illustrating how her trust increased over time at overnight camp. She explained that initially she didn't trust the chef, the counsellors, or the meals, but did trust her long time childhood friend Kate, also attending camp, who refrained from eating allergenic foods: "She tries not to eat what I am allergic to around me, and when I go to her house, nobody eats anything". Most children reported trusting friends also attending camp. This was most noticeable in older, more independent children, where the reliance on authority and adults was less. Although many of the participants' friends were food allergy aware, most did not have food allergies. John, 10 years old with peanut and tree nut allergy, echoed Jessica's sentiment about being with friends at camp, "It is easier to be with friends, because we protect each other".

While Jessica trusted friends the most at camp, over time she learned to trust the camp staff as well. At a previously attended overnight camp, she spoke about feeling unsafe and explained that a specific chef dedicated to preparing food (allergies) had been in close proximity to other campers foods: "some people ate stuff that I am allergic to". At the most recent summer camp, she explained that the initial orientation, when her counselor toured her around the kitchen and explained the ways in which they endeavor to make the camp safe, was most helpful and increased her level of trust with staff, counselors and the camp in general. She noted: "My counsellor talked to me, and he showed me the kitchen”. Her illustration (Figure 1 Jessica's illustration) reveals her initial anxiety writing: " $P m$ worried". However, over the course of the week, Jessica learned to trust the camp environment and enjoy eating without worrying about the safety of the food.

A surprising perspective emerged related to close contacts like family and friends being the most likely to bully those interviewed should be noted. For example, Michael a 7 year old male with dairy, egg, peanut, tree-nut, and fish allergy, said: “... I was friends with him. I told him to stop a couple of times, but he put [the Kit Kat] like right in my face". The frequency and type of bullying in this group was similar to other research results that found one in four children and young adults with food allergy has been bullied, teased, or harassed because of their food allergy [54].

Another factor that determined level of trust related to distant proximity with overnight camps and was expressed by Thomas, a 9-year-old male with peanut and tree nut allergy, when asked about whether he ever wanted to go to an overnight camp, he responded: "Probably not ... they probably have to call the ambulance, it would probably take about thirty minutes for them to come, so I just don't want to do it." In contrast, other responders felt the overnight camp setting was a safer and more controlled environment. For example Jessica said, "Because like overnight camps, nobody brings their own food, so they all have to eat what is there, so there is no sesame or peanuts." 


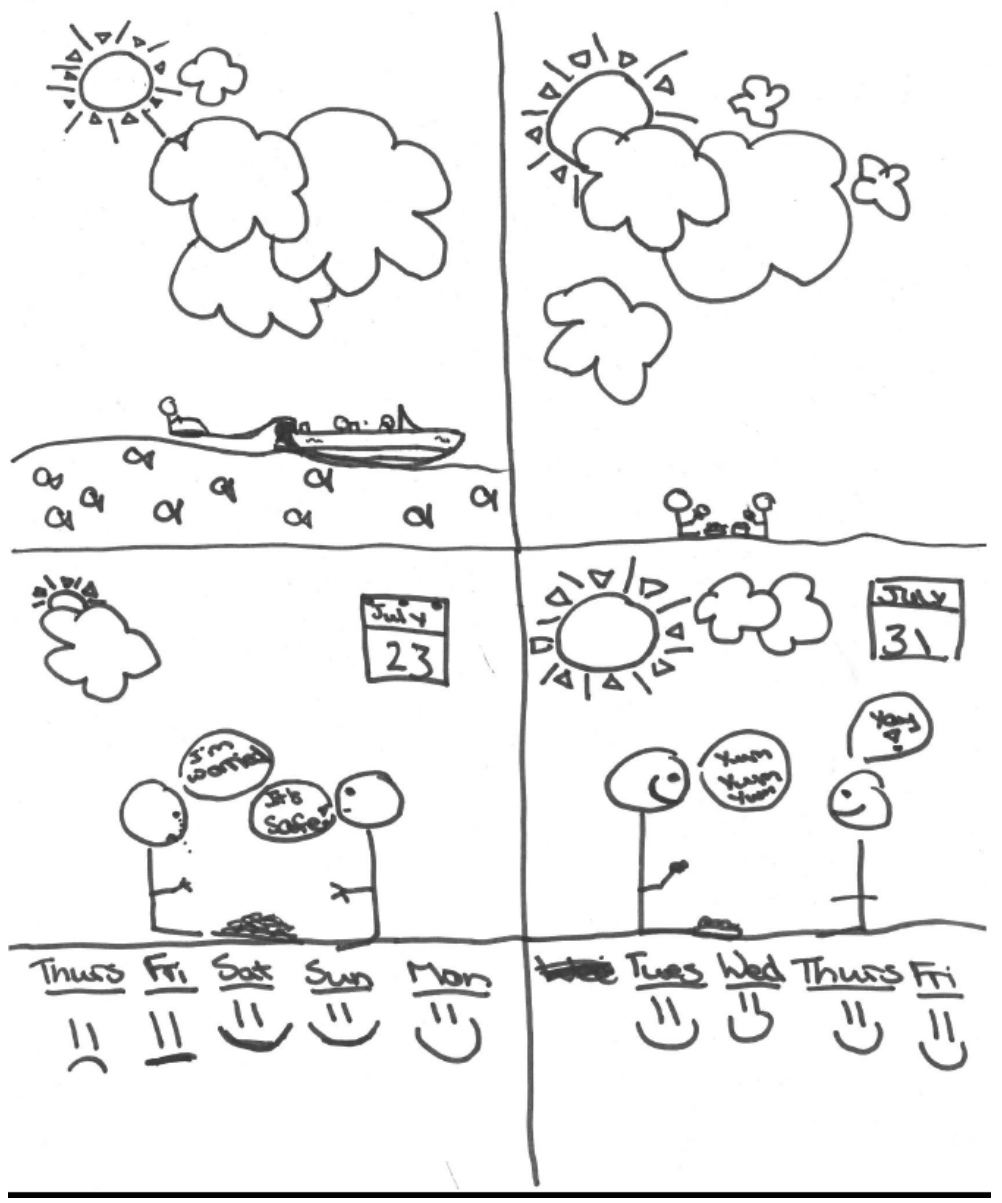

Figure 1. Jessica, 12, illustrates how her level of trust changed over the course of the camp.

For many, trust seemed related to limiting the number of unknown sources of allergen exposures. While eating areas such as dining halls posed obvious challenges, for some, just being outside introduced uncertainty about unpredictable sources of allergens. Sandra, a 11-year-old girl, with egg, milk, soy, tree nut, and sesame allergy talked about exposures outdoors as being unsafe, in this way: "If it was windy outside, I sort of sat the opposite way to the way the wind was blowing." Nick, a 7-year-old boy with egg, peanut, and tree nut allergy addressing unsafe areas at camp, said: "Sometimes where the squirrels are and sometimes like in the open, because there might be peanuts because of the squirrels.

One way to limit unknown allergen exposures is to limit certain allergens at camp and in fact many Ontario area day camps have policies that state they are either nutfree or nut-allergy friendly. Yet in this study, despite best intentions of camp directors to maintain a nut free or nut allergy friendly environment, many respondents reported frequent allergen exposures from other campers who brought packed lunches from home. For instance, Thomas, 9-year-old with peanut, tree nut, and sesame allergy, reported multiple exposures at different "nut-free" overnight and day camps, he noted: "for tennis camp there was like a cafeteria with tables, but we already brought our own 
food and a lot of people had nuts, like at another table AND [at a different camp] there were vending machines with stuff that didn't have labels, but contained nuts'.

\subsection{Coping Mechanisms}

All respondents talked about developing logistical coping strategies such as sitting near exits or positioning themselves at the end of lunch tables to limit potential allergen exposures and facilitate easy escape in case of exposure during meal times. While some respondents sat between trusted friends, many younger children were accompanied by adults. For instance, Sam, a 7-year-old boy with allergies to egg, peanut, tree nut, fish and shellfish, explained that he ate lunch with a nanny at school: "Our nanny has lunch with me every day, and sits at our own table, so we eat separately." Other patterns discussed by all age groups were the vigilant attention they had to hygiene (hand-washing). For example, John, 10-year-old with peanut and tree nut allergy, talked about how he handled a circumstance if someone touched him with peanut, "I would just ask my teacher or counsellor if I can go wash my hands, so it is not on me, I will use a cloth and if they don't, I will use my hand, and wash my hand after." Most children were vigilant about label reading as a normal management approach; for example, Michael, an 8 years old boy with milk, egg, peanut, tree nut, and fish allergy, said: "I read for my allergies basically, like if it says may contain peanut". These management strategies empowered participants by giving them some control over their environments, which helped to reduce the stress of worrying about exposure to food allergens.

In this study, both younger and older aged children coped in different ways when dealing with exposure to food allergens. For instance, both Charlotte, a 7-year-old girl with peanut and tree nut allergy, and Sam, aged 7, revealed a sense of immaturity and extreme responses to previous exposures: Charlotte noted: "Scrambled eggs are gross. They just taste gross. I never want to eat them, even if I wasn't allergic. I don't like the way they look or smell either." Similarly, Sam described his visceral response to contact with food allergens: "I would just tell them to not touch me after without wiping their hands and their face. And if they tried to touch me I just punch them."

Older responders discussed adjusting to normalizing their symptoms and rationalizing their behaviors. For example, Sandra explains: "When people drink milk they are drinking other species' milk, which I don't understand why you would do that." Interestingly, younger children alluded to their food allergies as making them feel "special" and allowing them to do activities other children couldn't do. This was commonly seen with younger children when they described how they brought non-allergenic cupcakes from home to birthday parties. Michael's picture illustrated this special attention in the camp setting when describing being driven around in a golf cart after developing hives: "I just draw awesome and put some other smiley faces around it." This perspective seems to be fostered by parents as a way to deal with their children being excluded from certain activities and at times needing medical attention.

\subsection{Proactive Parents}

Regardless of age, parents played a big role in how their children navigated the risk- 
scape of everyday life. For parents, it is a careful balance between ensuring their child's safety while also allowing them to develop independence and healthy coping mechanisms. The initial parental dependence we see in younger children keeps protective parents centrally involved as protector, which may delay the development of healthy coping strategies. In this study, many of the parents were involved in teaching other caregivers how to recognize the symptoms of anaphylaxis and instruct them in using selfinjectable epinephrine. Prior to enrolling their children in the camp, parents extensively researched the food preparation policies of the camp and in many cases provided input on the menu. In this highly informed and motived group, parents frequently went to extremes to provide their children with a "normal" but safe experience at camp. For example, one parent sent a list of all precautions (e.g. hand washing, wiping down counters) to ensure her son's safety. Another parent prepared all the required, safe foods for every meal for the week, while also staying nearby out of sight; yet, 11-yearold Sandra, revealed: "Yea, I saw her once, but it was by accident" (Figure 2 Sandra's Illustration).

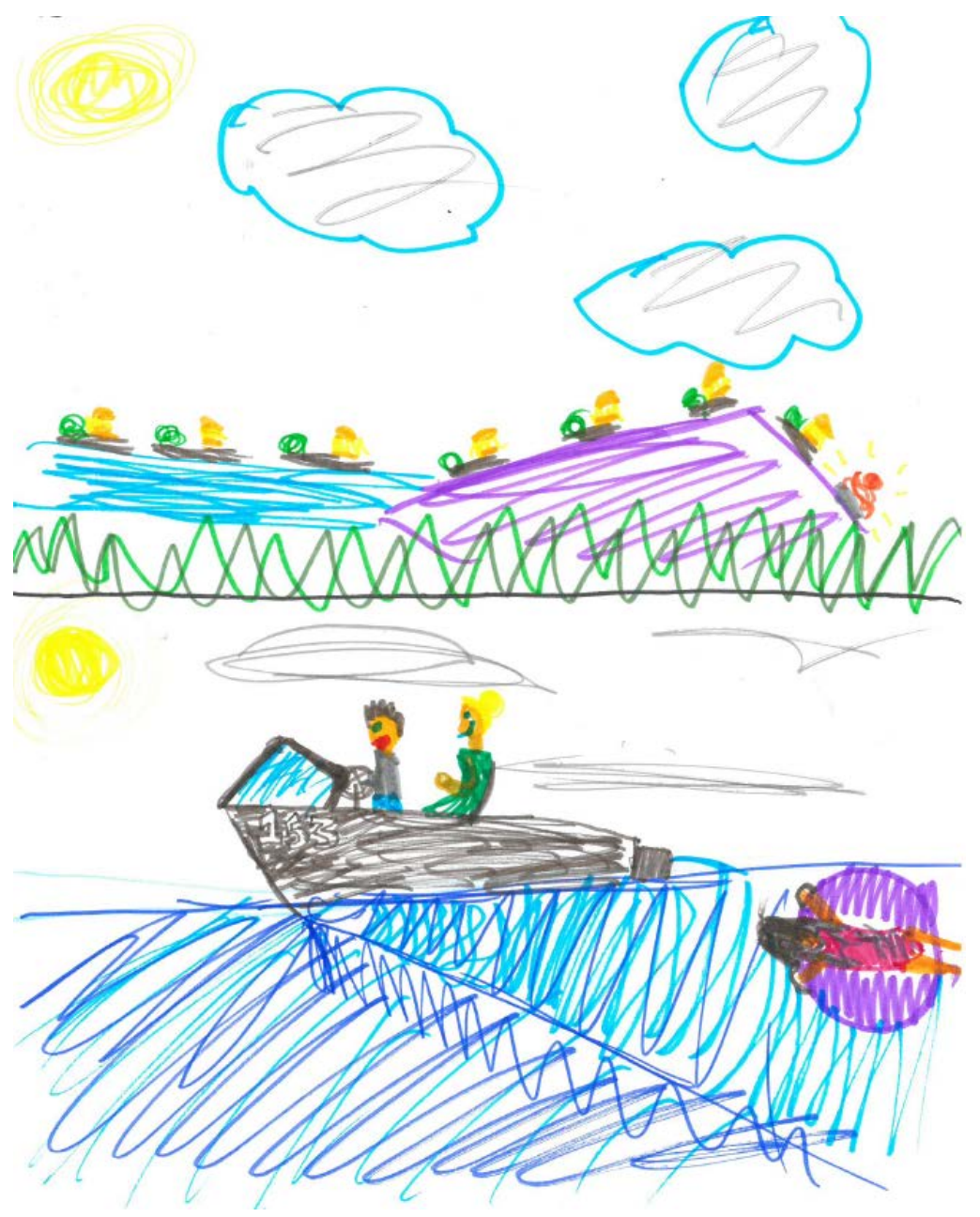

Figure 2. Sandra, 11yo whose parents were heavily involved in planning meals for her child, stayed out of sight (1st slide), so that the child was able to have a "regular" camp experience. 
In the transition from younger child to teen aged youth there appeared to be a window where they become more involved in decision-making about their food allergies. In general, families decided how much they wanted to control their children's environment by understanding the potential adverse affects on quality of life and willingness to trust their children to deal with risk on their own. Even though many summer camps in Ontario are accommodating children with food allergies, they seem to do so in different ways by providing them with "safe" environments and alternative menus. In this regard, they are serving as a partner with parents in helping children with food allergies improve their quality of life by reducing some of the exclusion and anxiety that can be inherent to food allergies.

\subsection{Camp Accommodation}

In general, camps endeavor to accommodate the seemingly growing food allergy population. These accommodations tend to include a range of approaches, such as eliminating top allergens from their menus, developing policies to regulate allergens that were brought into the camp by campers, and training personnel to manage food allergy emergencies. While many camps are designated as "food-allergy friendly" or "nut-free", camps are not regulated in the same way as schools. In this study, how unregulated camp environments managed food allergy policies were quite variable. Some of the more rigorous camp policies included the use of allergy boards and lunch checks. Anne, age 8 , peanut, tree nut, sesame allergy, felt safe knowing ingredient information for foods was visible: "It was an allergy board. So if there was tomatoes in it then they listed it on the allergy board, what was in the meal that they served." (Figure 3 Anne's illustration).
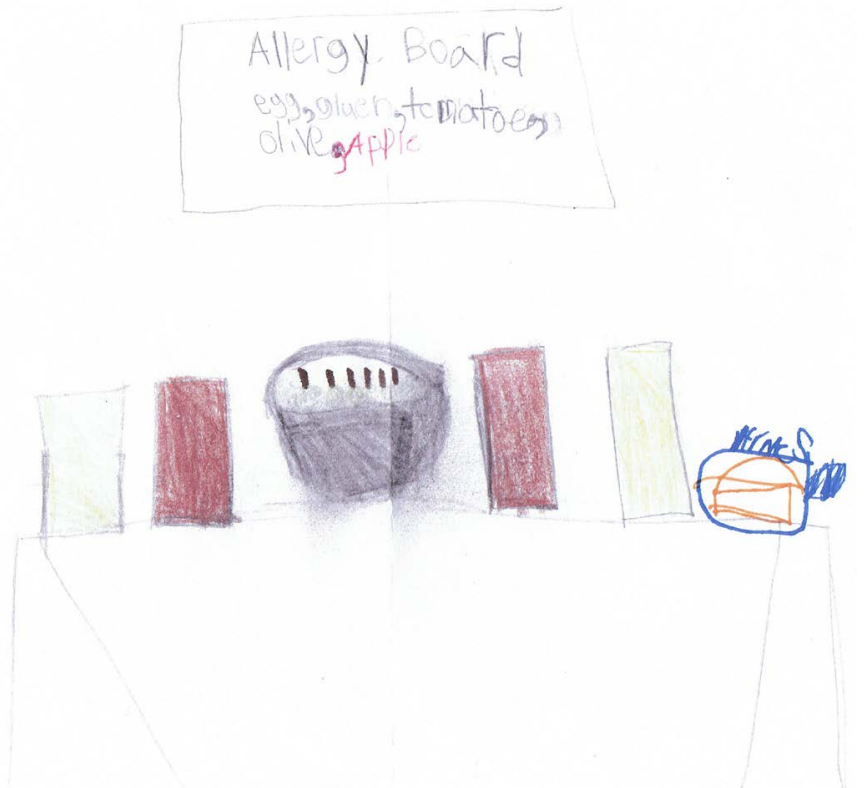

Figure 3. Anne, 8, illustrates how the camp accommodated her food allergies with a food allergy board. 
Another camper Sam, described the camp procedures that made him feel safe: "two counselors would hand out the wipes and then one counselor would sit in the middle, and then one other counselor would just sweep the floor, and clean up. The counsellors also looked at everyone's lunch [for allergens], except for ours'. By working with children with food allergies and their parents, camps were able to increase the confidence families had in letting their children attend camp. When asked about ways to make camp even safer for them, participants identified several suggestions (Table 2). For example, John, a 10-year-old boy with peanut and tree-nut allergy, recommended: "Put up a sign when the buses come that says don't bring nuts or peanuts to camp, or else you are going to have to throw it out." Sandra, emphasized normalizing food options: "It would be better if they have foods [for campers with food allergies] that were more similar to the other camper's food'. An important caveat to these accommodations is that many food allergy policies can be put in place, but that there is always the possibility of a mistake or rule being broken as experienced by Jessica: "Some other campers went to the city to go shopping, and they brought back a lot of candy, and they had a lot of Reece's Pieces, but they didn't open it, and it got taken away."

Camp Accommodations and Primary Theme addressed.

\section{Discussion}

By interviewing children at risk for food-related anaphylaxis, we were able to gain psychosocial and practical insights about how they are able to successfully navigate the potential risks at summer camp environments. These insights may be useful in informing future generations of children with food allergies about various management strategies and different ways that caregivers and organizations can assist. The scope of this study centered on the summer camp environment, but some of the findings may be considered for other unregulated environments. The themes from this data focused our conversation around four interrelated themes: trust, camp accommodation, coping mechanisms, and proactive parents.

Table 2. Camp Accommodations in Day and Overnight Camps. Theme addressed: Building trust (B), Accommodation (A), Proactive parents (P), Coping Mechanism (C).

\begin{tabular}{|c|c|c|}
\hline Overnight & Day-camp & Both \\
\hline $\begin{array}{l}\text { Food allergy } \\
\text { boards (A) }\end{array}$ & $\begin{array}{l}\text { Checking all lunches brought } \\
\text { from home }{ }^{*}(\mathrm{C})\end{array}$ & $\begin{array}{l}\text { Regular reminders to all } \\
\text { campers of camp food } \\
\text { allergy precautions (B) }\end{array}$ \\
\hline $\begin{array}{l}\text { Camper family } \\
\text { involvement } \\
\text { in menu design }(\mathrm{P})\end{array}$ & $\begin{array}{c}\text { For temporary day camps in public areas, } \\
\text { assessing for preexisting allergen exposures } \\
(\text { i.e. vending machines, people feeding squirrels })^{\star}(\mathrm{B})\end{array}$ & $\begin{array}{l}\text { Monitoring during } \\
\text { meal times* }(\mathrm{C})\end{array}$ \\
\hline $\begin{array}{l}\text { Camp Orientation } \\
\text { (Kitchen, Dining area, } \\
\text { Nurse location) (B) }\end{array}$ & & $\begin{array}{l}\text { Alternate activities for } \\
\text { those activities which } \\
\text { may contain allergens } \\
\text { (i.e. cooking/crafts) (A) } \\
\text { Open dialogue with } \\
\text { individual families } \\
\text { regarding needs } \\
\text { and expectations }(\mathrm{P})\end{array}$ \\
\hline
\end{tabular}

*Particularly for younger campers given developing comprehension and cognitive skills. 
Aside from the provision of medications (most importantly epinephrine) for symptomatic treatment, management of life-threatening reactions is limited to strict avoidance of implicated allergenic foods [55] [56]. The constant threat of exposure means food-allergic children and their families must remain vigilant [55]. Despite best efforts to maintain control and safety at home, parental worry often escalates due to a potential risk of exposure and lack of control when children go to camp, as approximately half of fatal reactions result from food consumed away from home [57]. Although there is limited specific data on the camp environment, parallels may be drawn with families "dining out". For example, Avery and colleagues (2003) found that families frequently visit the same restaurant because they trust the establishment and know their food allergy will be catered for [26].

We initially suspected there would be more concern about attending an overnight camp versus a day camp given the extended separation from trusted caregivers and reliance on food preparation from unknown individuals. However, the findings from our study showed that trust issues exist regardless of the type of camp experience (day or overnight). We found that it was through established camp procedures and accommodations that participants built trust over time. Expert-informed guidelines for managing food allergies at camp have been published in print and online in the United States [58] [59], but these procedures focus exclusively on safety recommendations for the family, camper, and camp. While there is some overlap with the results from our study, the guidelines do not reflect a child's quality of life perspective and ways to enhance camp experiences for those with food allergies. Many of the camps' accommodations enabled the children in this study to feel safe and less anxious, and may serve as a model for camps wishing to accommodate children with food allergies.

While participants in this study identified specific camp accommodations that helped build trust between family and camp, the research also exposes a fine line with accommodations that may be too draconian and difficult to control [60]. In this study, all the camps attended by participants were either "nut-free or nut friendly". However, accidental exposures happen at nut-free camps just as they do in nut-free schools. One school-based study showed that despite peanut and tree-nut free school policies, upwards of $19 \%$ reported a reaction still occurred [61]. There are no controlled trials to compare outcomes in schools and camps where peanuts are banned versus not banned. Experts in the field of food allergy have postulated bans may be reasonable for younger age groups (pre-school and lower elementary) as younger children are more likely to touch each other and contaminate each other's food [59]. As seen in our study, a major issue with enacting such "nut-bans" in camps is the age diversity of children and youth. Specifically, these bans apply a "one size fits all" approach where policies that are developmentally appropriate for elementary school aged children may not be appropriate for adolescents when risk taking, independent decision making, and self-efficacy skills are being developed.

One could argue that children do not experience their food allergies in a vacuum, and the real-world experiences at school and camp shape how they cope with adversity, 
as they grow older. While parents may endeavor to protect their child with food allergies, they also need to foster skills and confidence for children to ultimately become self-reliant. This is where we see the intersection between coping mechanisms and proactive parents lies. The families in this study had decided to allow a certain amount of risk into their child's life in order for them to experience normalizing activities.

There are a number of limitations to the study that need to be mentioned. Because of the nature of qualitative research, the sample size is smaller and there is not a control group for comparison. As this is a novel exploratory study intended to identify gaps and inform future food allergy management, the chosen approach is appropriate. However, utilizing a mixed-methodology approach (including quality of life scores) may provide broader implications in the future. Another limitation is that there is not a standardized food allergy quality of life questionnaire that is filled out by children under 8. We utilized the standardized parental form to address this population. We found that the younger children that we interviewed were quite knowledgeable about their food allergies and in expressing their feelings. To this point, the children that were interviewed were highly motivated and informed as they were recruited from a volunteer food allergy registry and regional food anaphylaxis group. Furthermore, these children were recruited from the province of Ontario, Canada. Therefore, it is possible, that the findings from this study may not be generalizable to other populations of children with food allergies.

The findings from our study show that empowerment starts at a young age and involves teaching children to read ingredients, learning about their food allergies, developing skills in dealing with inevitable accidents, developing proficiency using self-injectable epinephrine or seeking out help from someone who does, and educating supportive friends. As these children grow older, it is important for them to learn to make their own food choices and ask questions when they have doubts.

Similarly to what has been suggested for regulated school environments [1], a pediatrician or allergist can play a key role in ameliorating parental concerns about sending their children to camp and mediate an evidence-based plan that may ensure patient safety and cooperation. These plans may include kitchen and dining area orientation, involvement in menu design, allergy safety boards in dining halls, and camp reminders about food allergic children. Ultimately, the allergist can help provide an individualized plan, that can be tailored based on age, and can build trust as opposed to broad policies, like "peanut bans", that may not ensure safety or be developmentally appropriate.

\section{Conclusion}

Similar to what is being seen in schools across North America, the results of this study emphasize the need for specific interventions and improvements in health policies to support unregulated environments such as camps to deal with allergic children, ensuring their safety and psychological well-being. To our knowledge, this is the first study to address the needs of children with food allergies in camps from their perspective. Ultimately, individualized plans may be the best strategy in the camp-setting as the number 
of allergic triggers and severity of reactions can vary. Over-reaching policies are unlikely to be effective or adhered to by the non-allergic population. Developmentally appropriate policies in unregulated environments that allow for children with food allergies to make choices for themselves, such as were they chose to sit at mealtime? give them food options, and allow them to educate peers that may empower children with food allergies and increase self-efficacy, self-esteem and quality of life.

\section{Acknowledgements}

The authors acknowledge Camp Tamarack and the families involved in the study for their input. Funding for this grant was provided by the University of Waterloo, Center for Disease Prevention Institute Seed Grant. Development of Interview questionnaires was conducted with assistance from Alette C. Coble-Temple and the John F. Kennedy University Psychology Department. Kindercare Pediatrics' Dr. Daniel Flanders and Ms. Maggie Murray were instrumental in logistical considerations.

\section{Conflicts of Interest}

The authors declare that there is no conflict of interest regarding the publication of this article.

\section{References}

[1] Mudd, K. and Wood, R.A. (2011) Managing Food Allergies in Schools and Camps. Pediatric Clinics of North America, 58, 471-480. http://dx.doi.org/10.1016/j.pcl.2011.02.009

[2] Soller, L., Ben-Shoshan, M., Harrington, D., Knoll, M., Fragapane, J., Lawrence Joseph, J., St. Pierre, Y., La Vieille, S., Wilson, K., Elliott, S. and Clarke, A. (2015) Adjusting for Nonresponse Bias Corrects Overestimates of Food Allergy Prevalence. Journal of Allergy and Clinical Immunology: In Practice, 3, 291-293. http://dx.doi.org/10.1016/j.jaip.2014.11.006

[3] Briery, B.G. and Rabian, B. (1999) Psychosocial Changes Associated with Participation in a Pediatric Summer Camp. Journal of Pediatric Psychology, 24, 183-190. http://dx.doi.org/10.1093/jpepsy/24.2.183

[4] Török, S., Kökönyei, G., Károlyi, L., Ittzés, A. and Tomcsányi, T. (2006) Outcome Effectiveness of Therapeutic Recreation Camping Program for Adolescents Living with Cancer and Diabetes. Journal of Adolescent Health, 39, 445-447.

[5] Bollinger, M.E., Dahlquist, L.M. and Mudd, K. (2006) The Impact of Food Allergy on the Daily Activities of Children and Their Families. Annals of Allergy, Asthma \& Immunology, 96, 415-421. http://dx.doi.org/10.1016/S1081-1206(10)60908-8

[6] Rachul, C. and Caulfield, T. (2011) Food Allergy Policy and the Popular Press: Perspectives from Canadian Newspapers. Journal of Asthma and Allergy Educators, 2, 282-287. http://dx.doi.org/10.1177/2150129711410691

[7] Sicherer, S.H., Noone, S. and Muñoz-Furlong, A. (2001) The Impact of Childhood Food Allergy on Quality of Life. Annals of Allergy, Asthma \& Immunology, 87, 461-464. http://dx.doi.org/10.1016/S1081-1206(10)62258-2

[8] Baiardini, I., Braido, F., Brandi, S. and Canonica, G.W. (2006) Allergic Diseases and Their Impact on Quality of Life. Annals of Allergy, Asthma \& Immunology, 97, 419-429. http://dx.doi.org/10.1016/S1081-1206(10)60928-3 
[9] Primeau, M.N., Kagan, R., Joseph, L., Lim, H., Dufresne, C., Duffy, C., Prhcal, D. and Clarke, A. (2000) The Psychological Burden of Peanut Allergy as Perceived by Adults with Peanut Allergy and the Parents of Peanut-Allergic Children. Clinical and Experimental Allergy, 30, 1135-1143. http://dx.doi.org/10.1046/j.1365-2222.2000.00889.x

[10] Avery, N.J., King, R.M., Knight, S. and Hourihane, J.O. (2003) Assessment of Quality of Life in Children with Peanut Allergy. Pediatric Allergy \& Immunology, 14, 378-382. http://dx.doi.org/10.1034/j.1399-3038.2003.00072.x

[11] Ravid, N.L., Annunziato, R.A., Ambrose, M.A., Chuang, K., Mullarkey, C., Sicherer, S.H., Shemesh, E. and Cox, A.L. (2012) Mental Health and Quality-of-Life Concerns Related to the Burden of Food Allergy. Immunology and Allergy Clinics of North America, 32, 83-95. http://dx.doi.org/10.1016/j.iac.2011.11.005

[12] Fenton, N.E., Elliott, S.J., Cicutto, L., Clarke, A.E., Harada, L. and McPhee, E. (2010) Illustrating Risk: Anaphylaxis through the Eyes of the Food-Allergic Child. Risk Analysis, 31, 171-183. http://dx.doi.org/10.1111/j.1539-6924.2010.01488.x

[13] Monks, H., Gowland, M.H., Mackenzie, H., Erlewyn-Lajeunesse, M., King, R., Lucas, J.S. and Roberts, G. (2010) How Do Teenagers Manage Their Food Allergies? Clinical \& Experimental Allergy, 40, 1533-1540. http://dx.doi.org/10.1111/j.1365-2222.2010.03586.x

[14] Sampson, M.A., Munoz-Furlong, A. and Sicherer, S.H. (2006) Risk-Taking and Coping Strategies of Adolescents and Young Adults with Food Allergy. Journal of Allergy and Clinical Immunology, 117, 1440-1445. http://dx.doi.org/10.1016/j.jaci.2006.03.009

[15] Akeson, N., Worth, A. and Sheikh, A. (2007) The Psychosocial Impact of Anaphylaxis on Young People and Their Parents. Clinical and Experimental Allergy, 37, 1213-1220. http://dx.doi.org/10.1111/j.1365-2222.2007.02758.x

[16] Fenton, N.E., Elliott, S.J. and Clarke, A.E. (2011) Tag, You're Different: The Interrupted Spaces of Children at Risk of Anaphylaxis. Children's Geographies, 11, 281-297. http://dx.doi.org/10.1080/14733285.2013.812273

[17] Teufel, M., Biedermann, T., Rapps, N., Hausteiner, C., Henningsen, P., Enck, P. and Zipfel, S. (2007) Psychological Burden of Food Allergy. World Journal of Gastroenterology, 13, 3456-3465. http://dx.doi.org/10.3748/wjg.v13.i25.3456

[18] Klinnert, M.D. and Robinson, J.L. (2008) Addressing the Psychological Needs of Families of Food-Allergic Children. Current Allergy and Asthma Reports, 8, 195-200. http://dx.doi.org/10.1007/s11882-008-0033-7

[19] Salvilla, S.A., Dubois, A.E., Flokstra-de Blok, B.M., Panesar, S.S., Worth, A., Patel, S., Muraro, A., Halken, S., Hoffmann-Sommergruber, K., DunnGalvin, A., Hourihane, J.O., Regent, L., de Jong, N.W., Roberts, G. and Sheikh, A. (2014) Disease-Specific Health-Related Quality of Life Instruments for IgE-Mediated Food Allergy. Allergy, 69, 834-844. http://dx.doi.org/10.1111/all.12427

[20] Muraro, A., Dubois, A.E., DunnGalvin, A., Hourihane, J.O., de Jong, N.W., Meyer, R., Panesar, S.S., Roberts, G., Salvilla, S., Sheikh, A., Worth, A. and Flokstra-de Blok, B.M. (2014) EAACI Food Allergy and Anaphylaxis Guidelines. Food Allergy Health-Related Quality of Life Measures. Allergy, 69, 845-853. http://dx.doi.org/10.1111/all.12405

[21] Knibb, R.C. and Stalker, C. (2013) Validation of the Food Allergy Quality of Life-Parental Burden Questionnaire in the UK. Quality of Life Research, 22, 1841-1849. http://dx.doi.org/10.1007/s11136-012-0295-3

[22] Cohen, B.L., Noone, S., Muñoz-Furlong, A. and Sicherer, S.H. (2004) Development of a Questionnaire to Measure Quality of Life in Families with a Child with Food Allergy. Journal of Allergy and Clinical Immunology, 114, 1159-1163. 
http://dx.doi.org/10.1016/j.jaci.2004.08.007

[23] Cortes, A., Castillo, A. and Sciaraffia, A. (2013) Development of the Scale of Psychosocial Factors in Food Allergy. Pediatric Allergy and Immunology, 24, 671-677. http://dx.doi.org/10.1111/pai.12123

[24] Marklund, B., Ahlstedt, S. and Nordström, G. (2006) Health-Related Quality of Life in Food Hypersensitive Schoolchildren and Their Families: Parents' Perceptions. Health and Quality of Life Outcomes, 4, 48. http://dx.doi.org/10.1186/1477-7525-4-48

[25] DunnGalvin, A., de Blok Flokstra, B.M., Burks, A.W., Dubois, A.E. and Hourihane, J.O. (2008) Food Allergy QoL Questionnaire for Children Aged 0-12 Years: Content, Construct, and Cross-Cultural Validity. Clinical \& Experimental Allergy, 38, 977-986. http://dx.doi.org/10.1111/j.1365-2222.2008.02978.x

[26] Flokstra-de Blok, B.M., DunnGalvin, A., Vlieg-Boerstra, B.J., Oude Elberink, J.N., Duiverman, E.J., Hourihane, J.O. and Dubois, A.E. (2009) Development and Validation of a Self-Administered Food Allergy Quality of Life Questionnaire for children. Clinical \& $E_{X}$ perimental Allergy, 39, 127-137. http://dx.doi.org/10.1111/j.1365-2222.2008.03120.x

[27] Valentine, G. (1997) Oh Yes I Can" “Oh No You Can't”: Children's and Parents' Understandings of Kid's Competence to Negotiate Public Safety. Antipode, 29, 65-89. http://dx.doi.org/10.1111/1467-8330.00035

[28] Holloway, S.L. and Valentine, G. (2001) Children at Home in the Wired World: Reshaping and Rethinking Home. Urban Geography, 22, 562-583.

http://dx.doi.org/10.2747/0272-3638.22.6.562

[29] Punch, S. (2000) Children's Strategies for Creating Playspaces: Negotiating Independence in Rural Bolivia. In: Holloway, S.L. and Valentine, G., Eds., Children's Geographies: Playing, Living, Learning, Routledge, London, 48-62.

[30] Thompson, J.L. and Philo, P. (2004) Playful Spaces? A Social Geography of Children's Play in Livingston, Scotland. Children's Geographies, 2, 111-130. http://dx.doi.org/10.1080/1473328032000168804

[31] Aitken, S. (2005) The Awkward Spaces of Fathering. In: van Hoven, B. and Horschelmann, K., Eds., Spaces of Masculinity, Routledge, London, 222-237.

[32] Jones, O. (2005) An Ecology of Memory, Self and Landscape. In: Bondi, L., Smith, M. and Davidson, J., Eds., Emotional Geographies, Ashgate, London, 205-218.

[33] Bondi, L., Davidson, J. and Smith, M. (Eds.) (2005) Emotional Geographies. Ashgate, Burlington.

[34] Mandell, D., Curtis, R., Gold, M. and Hardie, S. (2005) Anaphylaxis: How Do you Live with It? Health \& Social Work, 30, 325-335. http://dx.doi.org/10.1093/hsw/30.4.325

[35] Gillespie, C.A., Woodgate, R.L., Chalmers, K.I. and Watson, W.T. (2007) "Living with Risk": Mothering a Child with Food-Induced Anaphylaxis. Journal of Pediatric Nursing, 22, 30-42. http://dx.doi.org/10.1016/j.pedn.2006.05.007

[36] Mitchell, L.M. (2006) Child-Centered? Thinking Critically about Children's Drawings as a Visual Research Method. Visual Anthropology Review, 22, 60-73. http://dx.doi.org/10.1525/var.2006.22.1.60

[37] Christensen, P. and James, A. (2008) Childhood Diversity and Commonality: Some Methodological Insights. In: Christensen, P. and James, A., Eds., Research with Children: Perspectives and Practices, Routledge, New York, 156-172.

[38] Christensen, P. and Prout, A. (2006) Anthropological and Sociological Perspectives on the Study of Children. In: Greene, S. and Hogan, D., Eds., Researching Children's Experience: 
Approaches and Methods, Sage, Thousand Oaks, 42-60.

[39] O'Kane, C. (2008) The Development of Participatory Techniques: Facilitating Children's Views about Decisions That Affect Them. In: Christensen, P. and James, A., Eds., Research with Children: Perspectives and Practices, Routledge, New York, 125-155.

[40] James, A., Jenks, C. and Prout, A. (1998) Theorizing Children. Policy Press, Cambridge.

[41] Veale, A. (2006) Creative Methodologies in Participatory Research with Children. In: Greene, S. and Hogan, D., Eds., Researching Children's Experience: Approaches and Methods, Sage, Thousand Oaks, 253-272.

[42] Koppitz, E.M. (1968) Psychological Evaluation of Children's Human Figure Drawings. Grune and Stratton, New York.

[43] Mayall, B. (2008) Conversations with Children: Working with Generational Issues. In: Christensen, P. and James, A., Eds., Research with Children: Perspectives and Practices, Routledge, New York, 109-124.

[44] Punch, S. (2002) Research with Children: The Same or Different from Research with Adults? Childhood, 9, 321-341. http://dx.doi.org/10.1177/0907568202009003005

[45] Dreissnack, M. (2005) Children's Drawings as Facilitators of Communication: A MetaAnalysis. Journal of Pediatric Nursing, 20, 415-423. http://dx.doi.org/10.1016/j.pedn.2005.03.011

[46] Sartain, S.A., Clarke, C.L. and Heyman, R. (2000) Hearing the Voices of Children with Chronic illness. Journal of Advanced Nursing, 32, 913-921.

[47] Kostenius, C. and Ohrling, K. (2008) The Meaning of Stress from School Children's Perspective. Stress and Health, 24, 287-293. http://dx.doi.org/10.1002/smi.1180

[48] Handelman, L., Rich, M., Bridgemohan, C.F. and Schneider, L. (2014) Understanding Pediatric Inner-City Asthma: An Explanatory Model Approach. Journal of Asthma, 41, $167-$ 177. http://dx.doi.org/10.1081/JAS-120026074

[49] Rollins, J. (2005) Tell Me about It: Drawing as a Communication Tool for Children with Cancer. Journal of Pediatric Oncology, 22, 203-221. http://dx.doi.org/10.1177/1043454205277103

[50] Stefanatou, A. (2008) Use of Drawings in Children with Pervasive Developmental Disorder during Hospitalization: A Developmental Perspective. Journal of Child Health Care, 12, 268-283. http://dx.doi.org/10.1177/1367493508096203

[51] Kortesluoma, R.-L., Punamaki, R.-L. and Nikkonen, M. (2008) Hospitalized Children Drawing Their Pain: The Contents and Cognitive and Emotional Characteristics of Pain Drawings. Journal of Child Health, 12, 284-300. http://dx.doi.org/10.1177/1367493508096204

[52] Gibbs, G. (2002) Qualitative Data Analysis: Explorations with NVivo. Open University Press, Maidenhead.

[53] Miles, M.B. and Huberman, A.M. (1994) Qualitative Data Analysis: An Extended Sourcebook. 2nd Edition, Sage, Thousand Oaks.

[54] Lieberman, J.A., Weiss, C., Furlong, T.J., Sicherer, M. and Sicherer, S.H. (2010) Bullying among Pediatric Patients with Food Allergy. Annals of Allergy, Asthma, \& Immunology, 105, 282-286. http://dx.doi.org/10.1016/j.anai.2010.07.011

[55] Sicherer, S.H. (2002) Food Allergy. Lancet, 360, 701-710. http://dx.doi.org/10.1016/S0140-6736(02)09831-8

[56] Sampson, H.A. (2004) Update on Food Allergy. Journal of Allergy \& Clinical Immunology, 113, 805-919. http://dx.doi.org/10.1016/j.jaci.2004.03.014 
[57] Bock, S.A., Muñoz-Furlong, A. and Sampson, H.A. (2007) Further Fatalities Caused by Anaphylactic Reactions to Food, 2001-2006. Journal of Allergy and Clinical Immunology, 119, 1016-1018. http://dx.doi.org/10.1016/j.jaci.2006.12.622

[58] Greenhawt, M., Bradsher, J., Polmear-Swendris, N., McMorris, M. and Weiss, C. (2010) Food Allergy Preparedness of Summer Camps. Journal of Allergy and Clinical Immunolo$g y$, 125, AB60. http://dx.doi.org/10.1016/j.jaci.2009.12.958

[59] Rebull, H., Piper, C. and Cronin, G. Allergy \& Anaphylaxis Network. Food Allergies Management at Camp. http://www.foodallergy.org/file/camp-guidelines-faan.pdf

[60] Christakis, N.A. (2008) This Allergies Hysteria Is Just Nuts. BMJ, 337, 1384. http://dx.doi.org/10.1136/bmj.a2880

[61] Sicherer, S.H., Furlong, T.J., DeSimone, J. and Sampson, H.A. (2001) The US Peanut and Tree Nut Allergy Registry: Characteristics of Reactions in Schools and Day Care. Journal of Pediatrics, 138, 560-565. http://dx.doi.org/10.1067/mpd.2001.111821

\section{Submit or recommend next manuscript to SCIRP and we will provide best service} for you:

Accepting pre-submission inquiries through Email, Facebook, LinkedIn, Twitter, etc. A wide selection of journals (inclusive of 9 subjects, more than 200 journals)

Providing 24-hour high-quality service

User-friendly online submission system

Fair and swift peer-review system

Efficient typesetting and proofreading procedure

Display of the result of downloads and visits, as well as the number of cited articles

Maximum dissemination of your research work

Submit your manuscript at: http://papersubmission.scirp.org/

Or contact health@scirp.org 